\title{
Can Steam- and CO-rich Streams Be Produced Sequentially in the Isothermal Chemical Looping Super-Dry Reforming Scheme?
}

\author{
Xinhe Wang ${ }^{1}$, Jinjia Wei ${ }^{1,2}$, Junshe Zhang, ${ }^{2, *}$ \\ ${ }^{1}$ State Key Laboratory of Multiphase Flow in Power Engineering, X'an Jiaotong University, \\ Xi'an, Shaanxi 710049, China \\ ${ }^{2}$ School of Chemical Engineering and Technology, Xi'an Jiaotong University, Xi'an, Shaanxi \\ 710049, China \\ *jzhang08@xjtu.edu.cn (Junshe Zhang)
}

\section{Thermodynamic of reactions}

Figure S1. Experimental setup of performance testing.

Figure S2. XRD patterns of as-prepared redox materials.

Figure S3. Scanning electron microscope (SEM) image (a) and energy dispersive $\mathrm{X}$-ray (EDS) mappings (b) of as prepared $50 \mathrm{Fe}_{2} \mathrm{O}_{3} / \mathrm{MgAl}_{2} \mathrm{O}_{4}$ sample.

Figure S4. Reduction degree of $50 \mathrm{Fe}_{2} \mathrm{O}_{3} / \mathrm{MgAl}_{2} \mathrm{O}_{4}$ sample with a fully $\left(\mathrm{CO}_{2}\right)$ oxidized state at $750{ }^{\circ} \mathrm{C}: 0.1 \mathrm{~g}$ redox materials, $F_{\mathrm{Ar}}=50 \mathrm{STP} \mathrm{mL} / \mathrm{min}, 10$ consecutive pules of $0.55 \mathrm{~mL} \mathrm{H}$ at ambient conditions.

Figure S5. $\mathrm{H}_{2} \mathrm{O}$ and $\mathrm{H}_{2}$ signals of $\mathrm{H}_{2}$ pulses (a) and subsequent $\mathrm{CO}$ and $\mathrm{CO}_{2}$ signals of $\mathrm{CO}_{2}$ pulses (b) starting from a fully $\left(\mathrm{CO}_{2}\right)$ oxidized state at $750{ }^{\circ} \mathrm{C}: 1.0 \mathrm{~g}$ redox materials, $F_{\mathrm{Ar}}=50 \mathrm{STP} \mathrm{mL} / \mathrm{min}, 5$ consecutive pules of $0.55 \mathrm{~mL} \mathrm{H}_{2}$ followed by 5 consecutive pules of $0.55 \mathrm{~mL} \mathrm{CO}$ at ambient conditions.

Figure S6. Reduction degree of $50 \mathrm{Fe}_{2} \mathrm{O}_{3} / \mathrm{MgAl}_{2} \mathrm{O}_{4}$ sample with a fully $\left(\mathrm{CO}_{2}\right)$ oxidized state at $750{ }^{\circ} \mathrm{C}: 1.0 \mathrm{~g}$ redox materials, $F_{\mathrm{Ar}}=50 \mathrm{STP} \mathrm{mL} / \mathrm{min}, 55$ pules of 0.55 $\mathrm{mL} \mathrm{H}_{2}$ at ambient conditions. 


\section{Thermodynamic of reactions}

For a general reaction, the Gibbs energy change of reaction $\Delta G_{r}$ is determined by the following expression,

$$
\Delta G_{r}=\Delta G_{r}^{0}+R T \ln Q
$$

where $\Delta G_{r}^{0}$ is the Gibbs energy change per mole of reaction for pure reactants and products at $1 \mathrm{~atm}, R$ is the gas constant, $T$ represents the absolute temperature, and $Q$ is the reaction quotient.

When the reaction reaches equilibrium,

$$
\begin{aligned}
& \Delta G_{r}=0 \\
& Q=K_{e q}
\end{aligned}
$$

where $K_{\mathrm{eq}}$ is the equilibrium constant.

$$
\Delta G_{r}^{0}=-R T \ln K_{e q}
$$

The Ellingham diagram presents the standard Gibbs energy change of reactions $\left(\Delta G_{r}^{0}\right)$ versus temperature.

$$
\Delta G_{r}^{0}=\Delta H^{0}-T \Delta S^{0}
$$

where $\Delta H^{0}$ and $\Delta S^{0}$ are the change of standard enthalpy and entropy of reactions.

Although both $\Delta S^{0}$ and $\Delta H^{0}$ vary with temperature, the changes are so small as to be negligible. Thus, the lines in Ellingham Diagram are approximately straight. 


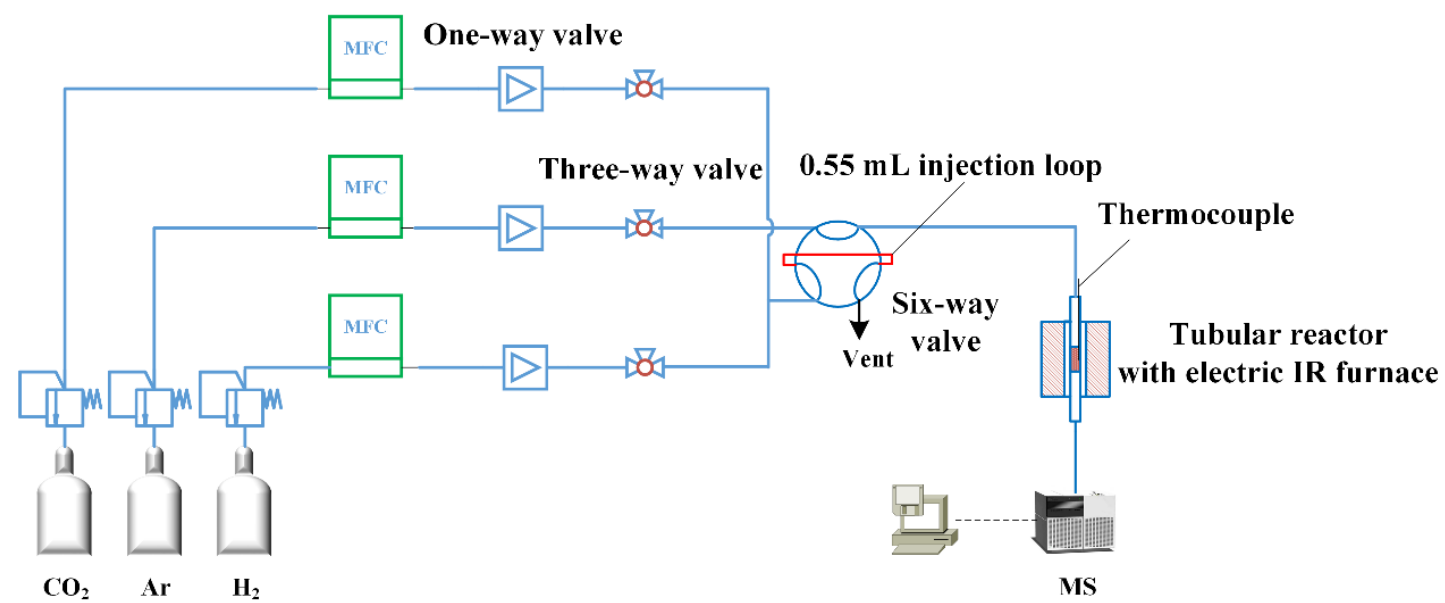

Figure S1. Experimental setup of performance testing. 


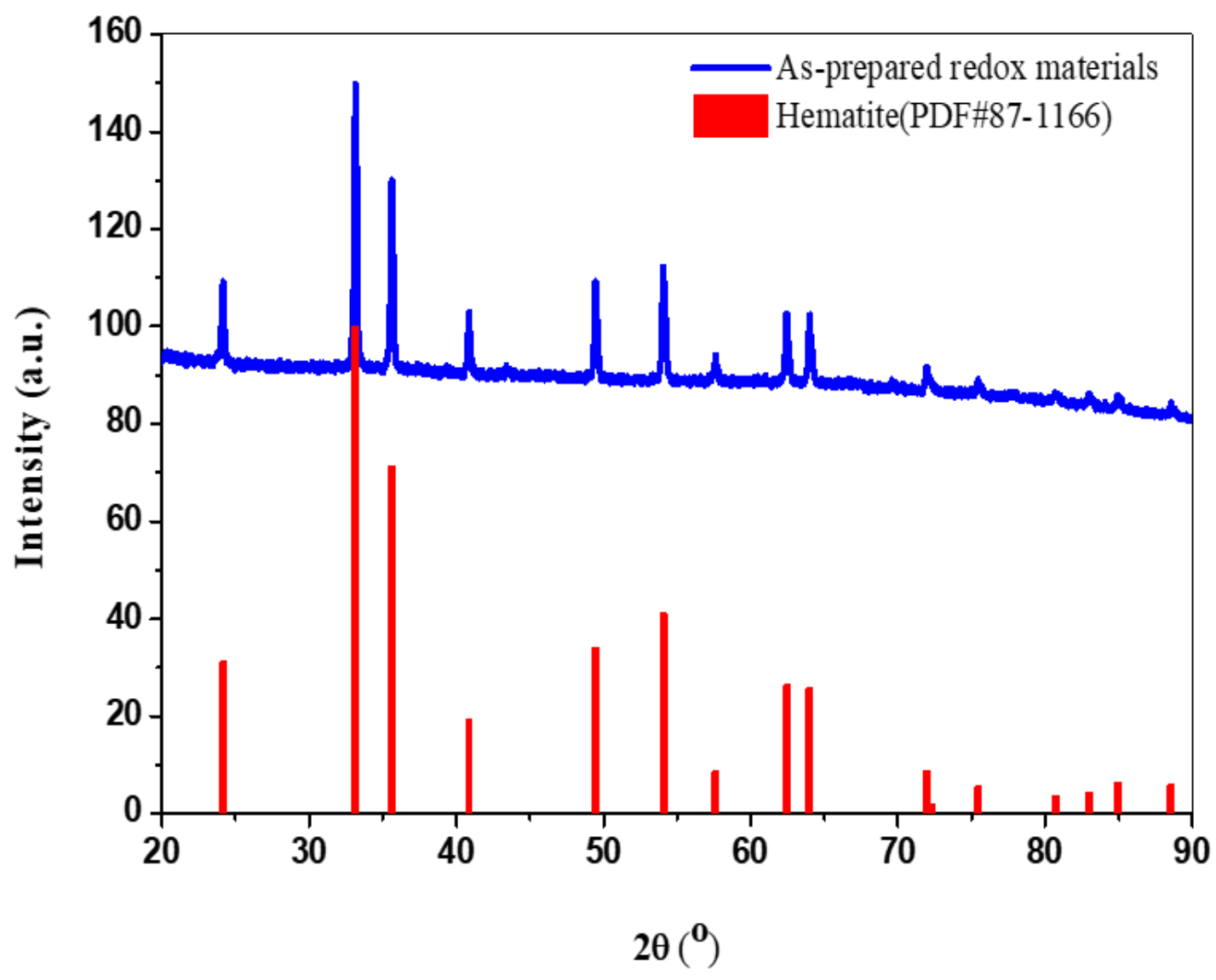

Figure S2. XRD patterns of as-prepared redox materials. 

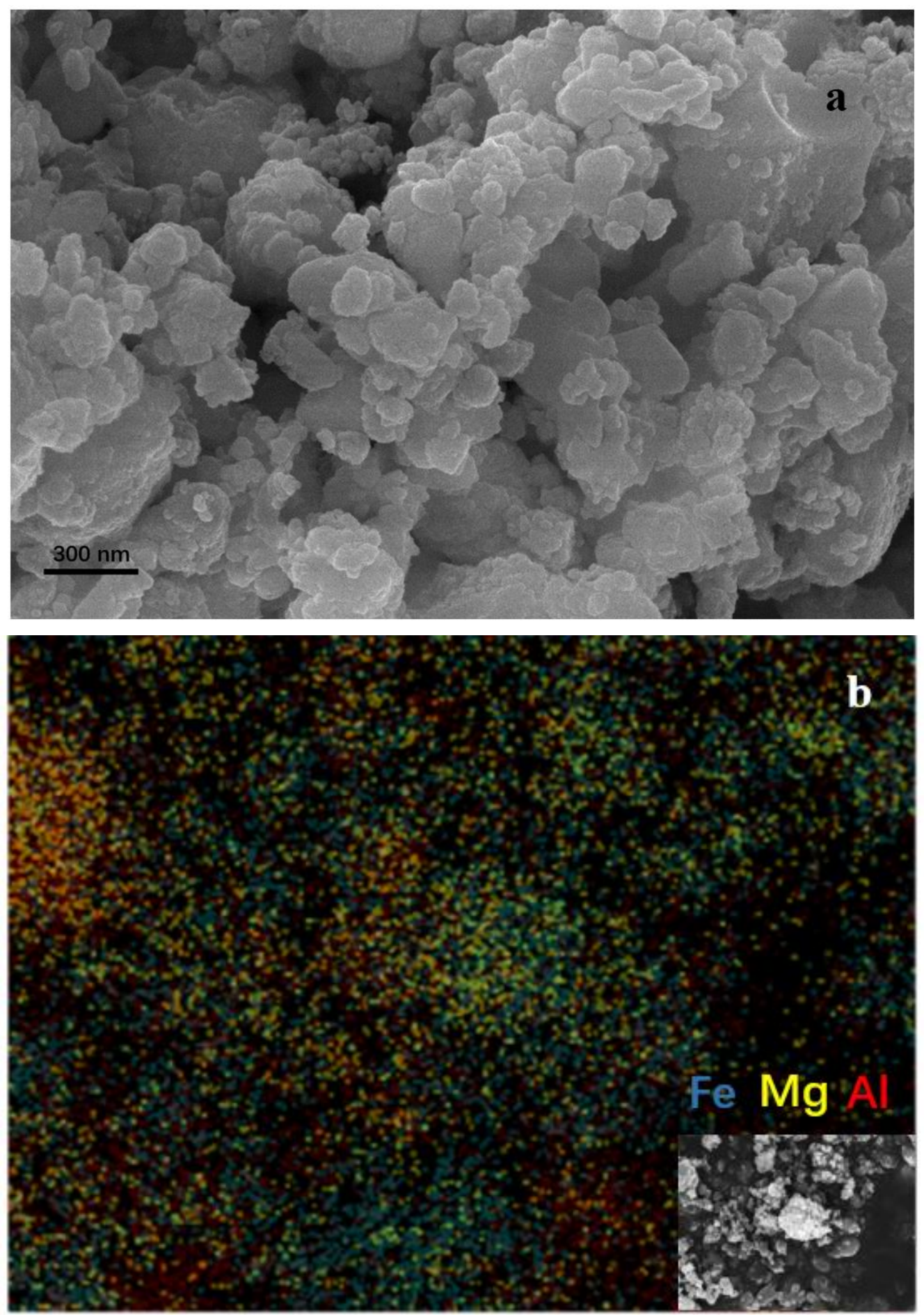

\section{$2.5 \mu \mathrm{m}$}

Figure S3. Scanning electron microscope (SEM) image (a) and energy dispersive $\mathrm{X}$-ray (EDS) mappings (b) of as prepared $50 \mathrm{Fe}_{2} \mathrm{O}_{3} / \mathrm{MgAl}_{2} \mathrm{O}_{4}$ sample. 


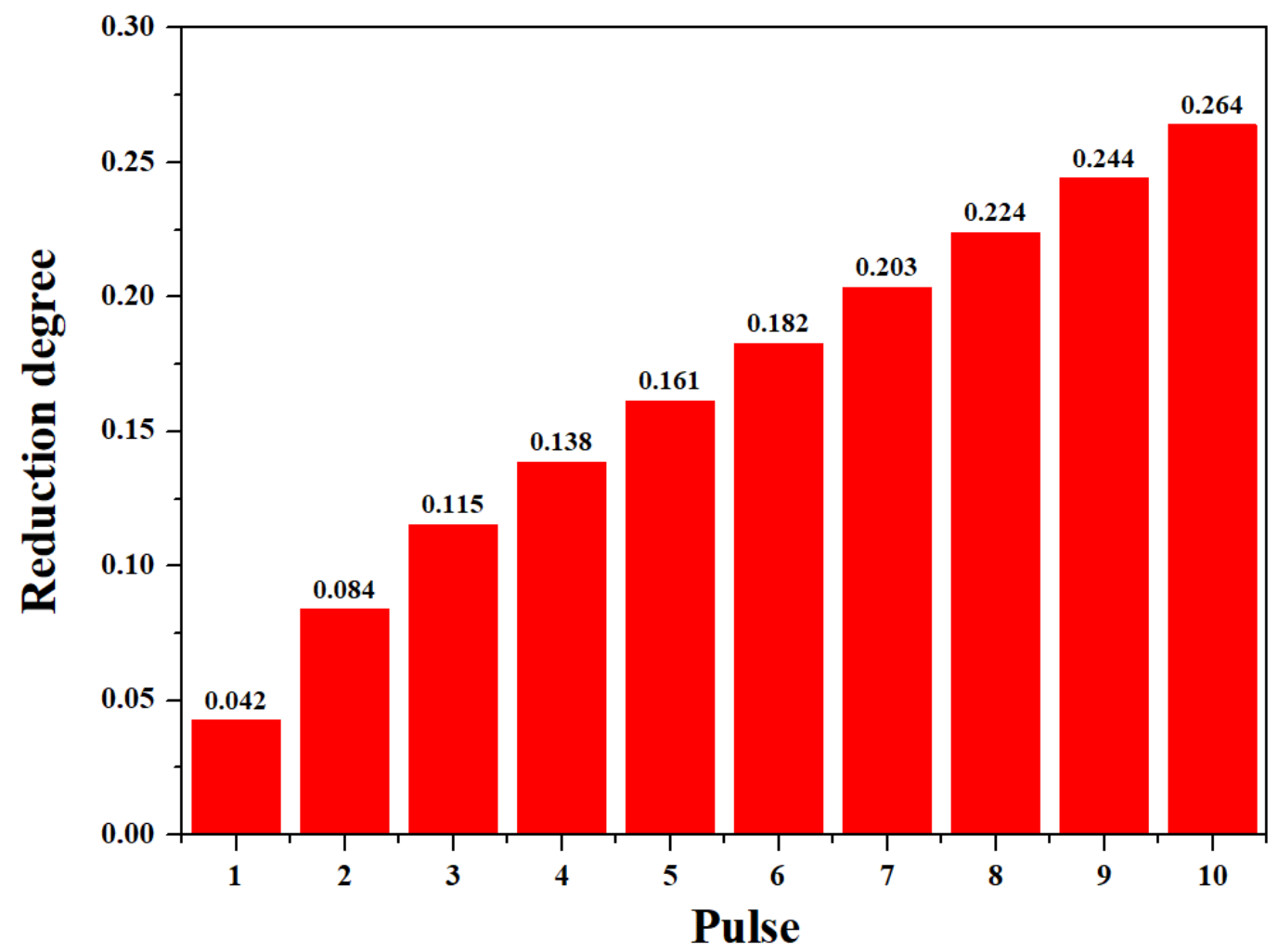

Figure S4. Cumulative reduction degree of $50 \mathrm{Fe}_{2} \mathrm{O}_{3} / \mathrm{MgAl}_{2} \mathrm{O}_{4}$ sample with a fully $\left(\mathrm{CO}_{2}\right)$ oxidized state at $750{ }^{\circ} \mathrm{C}: 0.1 \mathrm{~g}$ redox materials, $F_{\mathrm{Ar}}=50 \mathrm{STP} \mathrm{mL} / \mathrm{min}, 10$ consecutive pules of $0.55 \mathrm{~mL} \mathrm{H}$ at ambient conditions. 

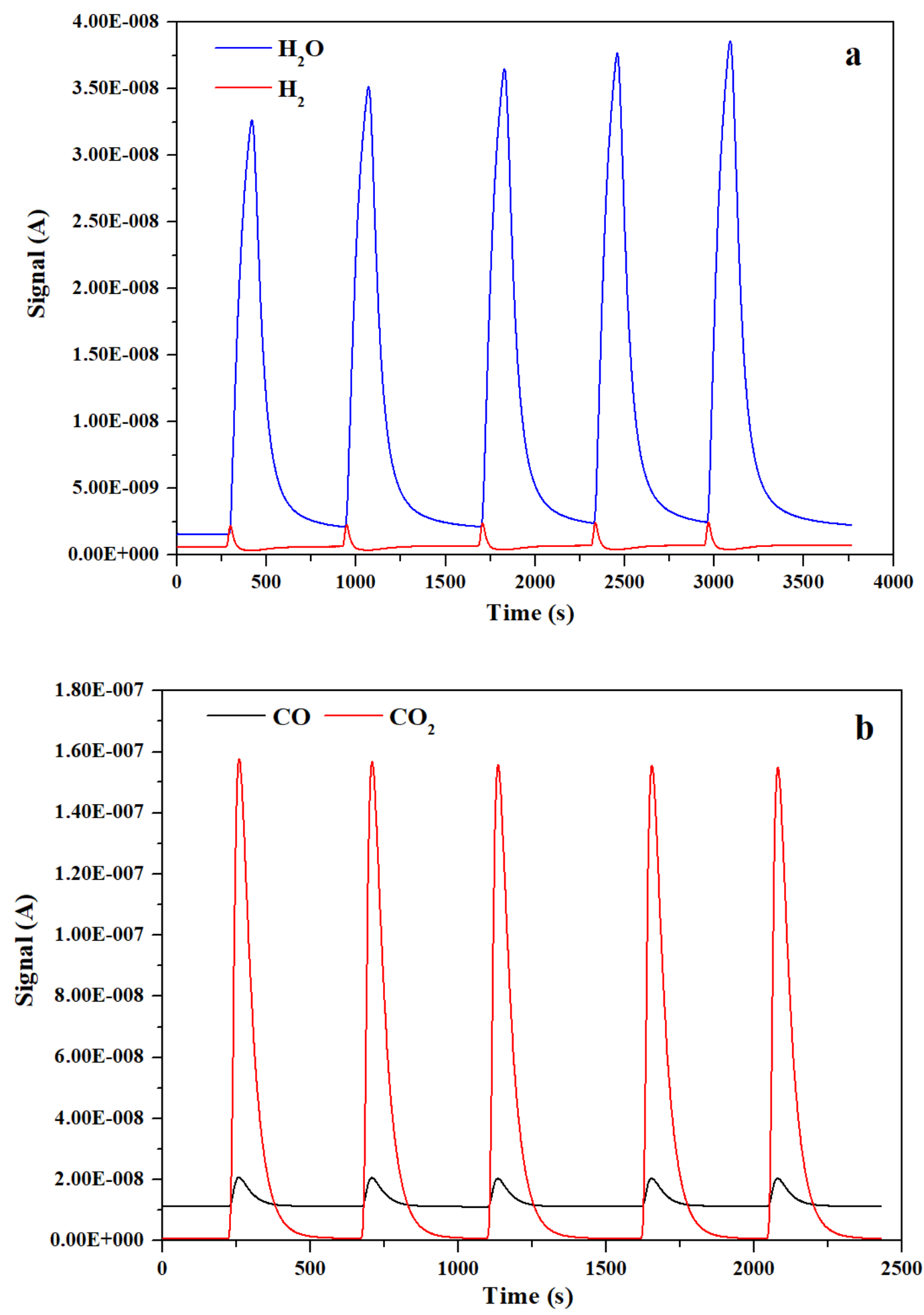

Figure S5. $\mathrm{H}_{2} \mathrm{O}$ and $\mathrm{H}_{2}$ signals of $\mathrm{H}_{2}$ pulses (a) and subsequent $\mathrm{CO}$ and $\mathrm{CO}_{2}$ signals of $\mathrm{CO}_{2}$ pulses (b) starting from a fully $\left(\mathrm{CO}_{2}\right)$ oxidized state at $750{ }^{\circ} \mathrm{C}: 1.0 \mathrm{~g}$ redox materials, $F_{\mathrm{Ar}}=50 \mathrm{STP} \mathrm{mL} / \mathrm{min}, 5$ consecutive pules of $0.55 \mathrm{~mL} \mathrm{H}_{2}$ followed by 5 consecutive pules of $0.55 \mathrm{~mL} \mathrm{CO}_{2}$ at ambient conditions. 


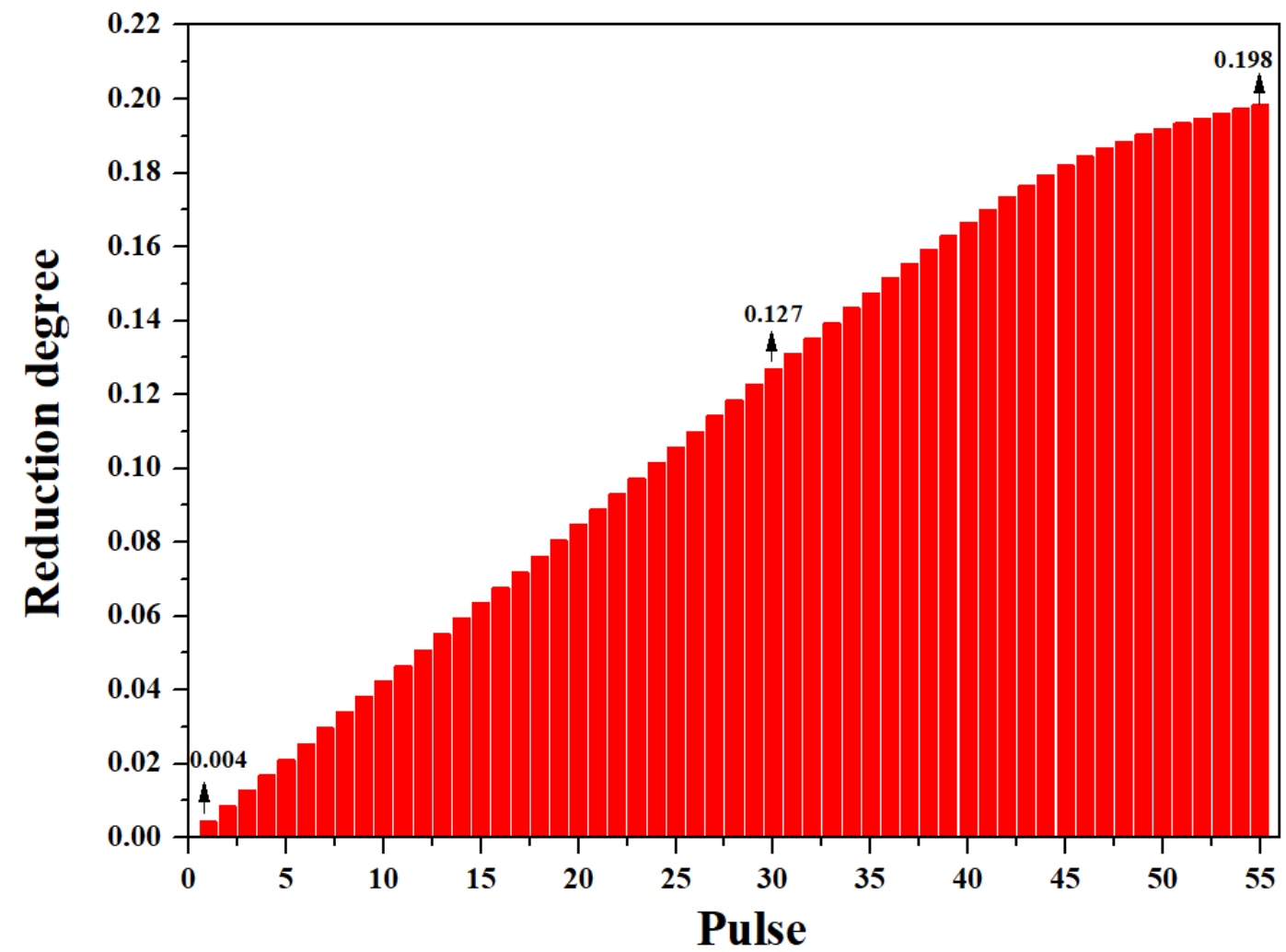

Figure S6. Cumulative reduction degree of $50 \mathrm{Fe}_{2} \mathrm{O}_{3} / \mathrm{MgAl}_{2} \mathrm{O}_{4}$ sample with a fully $\left(\mathrm{CO}_{2}\right)$ oxidized state at $750{ }^{\circ} \mathrm{C}: 1.0 \mathrm{~g}$ redox materials, $F_{\mathrm{Ar}}=50 \mathrm{STP} \mathrm{mL} / \mathrm{min}, 55 \mathrm{pules}$ of $0.55 \mathrm{~mL} \mathrm{H}_{2}$ at ambient conditions. 